\title{
Leptomeningeal Gliomatosis: A Single Institution Study of 31 Patients
}

\author{
DIDIER AUTRAN ${ }^{1}$, MARYLINE BARRIE ${ }^{1}$, MONA MATTA $^{1}$, COLETTE MONSERRAT $^{2}$, \\ CHANTAL CAMPELLO ${ }^{1}$, GREGORIO PETRIRENA ${ }^{1}$, CELINE BOUCARD $^{1}$, LAETITIA PADOVANI ${ }^{3}$, \\ ANDERSON LOUNDOU ${ }^{4}$, ROMAIN APPAY ${ }^{5}$, THOMAS GRAILLON ${ }^{6}$, HENRY DUFOUR $^{6}$, \\ DOMINIQUE FIGARELLA-BRANGER ${ }^{5,7}$, OLIVIER CHINOT ${ }^{1,7}$ and EMELINE TABOURET ${ }^{1,7}$ \\ Departments of ${ }^{1}$ Neuro-Oncology, ${ }^{3}$ Radiotherapy, ${ }^{5}$ Anatomopathology-Neuropathology, \\ ${ }^{6}$ Neuro-Surgery and ${ }^{2}$ Laboratory of Biochemistry, AP-HM, CHU Timone, Marseille, France; \\ ${ }^{4}$ EA 3279, and 7UMR7051, INP, Team 8, Aix-Marseille University, Marseille, France
}

\begin{abstract}
Background/Aim: Secondary leptomeningeal gliomatosis $(L G)$ is a rare and severe progression pattern of glioma. Our objective was to evaluate the characteristics and outcome of patients with LG. Patients and Methods: We retrospectively reviewed 31 patients diagnosed with secondary $L G$. At the time of $L G$ diagnosis, the median age of patients was 45 years. The histological grade was IV in 20 patients and II to III in 11 patients. As a first-line of therapy for $L G, 22$ patients received an oncological treatment: i) BCNU-temozolomide (TMZ) $(n=15)$, ii) other type of chemotherapy $(n=7)$, and iii) no treatment (supportive care) (n=9). Results: Following LG diagnosis, the median progression-free survival (PFS) and overall survival (OS) were 1.8 months [95\% confidence interval $(C I)=0.9-2.7]$ and 2.1 months $(95 \% C I=1.3-3)$, respectively. The univariate analyses showed an improved $O S$ with age of less than 45 years $(p<0.001)$, a prolonged interval from the initial glioma diagnosis (IGD) to $L G$ diagnosis ( $p=0.003$ ), BCNU-TMZ as the preferred first-line treatment for $L G$ out of the three options ( $p=0.008)$, and Karnofsky performance status $(K P S) \geq 70 \quad(p=0.012)$. Prolonged interval from $I G D$ to $L G$ diagnosis $(H R=5.839)$ and $B C N U-$ $T M Z$ as the chosen first-line treatment for $L G(H R=6.635)$ remained significant in the multivariate analyses as well. Among the 22 treated patients, the median OS was significantly higher $(p=0.008)$ with the BCNU-TMZ treatment (5.7 months; 95\%CI=4.2-7.1), compared to other
\end{abstract}

Correspondence to: Didier Autran, Assistance Publique des Hôpitaux de Marseille, Timone Hospital, Department of NeuroOncology, 264 rue saint Pierre, 13005, Marseille, France. Tel: +33 491984834, Fax: +33 491387348, e-mail: didier.autran@ap-hm.fr

Key Words: Glioma, leptomeningeal gliomatosis, prognostic factors, $\mathrm{BCNU}$, temozolomide. types of treatment offered (2 months; 95\%CI=1.1-2.9). Conclusion: The time interval from the IGD to the $L G$ diagnosis is a potential prognostic factor for $L G$. BCNUTMZ may be a therapeutic option in the present setting.

Primary diffuse leptomeningeal gliomatosis (LG) is a neoplasm confined to the meninges without evidence of a primary tumor in the brain or spinal cord parenchyma (1). In contrast, secondary diffuse LG is a rare and severe clinical metastatic complication resulting from the extension of a primary central nervous glioma (2). It has not been recognized as a distinct pathological disease entity by the $2016 \mathrm{WHO}$ classification of tumours of the central nervous system and as such, its occurrence is probably underestimated (3).

LG occurs when tumor glial cells disseminate into the cerebrospinal fluid (CSF) through its drainage channels, migrate to distant sites, form colonies, and multiply (4). The rate of secondary LG varies mainly between $1 \%$ to $15 \%$ in clinical reports $(2,5,6)$ and may increase up to $25 \%$ in autopsy reports (7). Recently, the incidence of secondary LG was found to be increasing, concomitant with the higher life expectancy of patients with glioma (2). However, to date, a consensus on the definitive diagnostic criteria of LG remains debatable, and is generally based on an association with certain pathological anomalies (8).

The clinical diagnosis of LG is challenging because of the polymorphous and unspecific symptoms varying according to the affected region in the central nervous system. Pleomorphic and multifocal neurological symptoms and signs, such as headache, cognitive disturbance and cranial nerve impairment (diplopia, dysphagia, dysarthia and hear loss) are observed in more than half of the patients with neoplastic meningitis (9). Head or back pain have been frequently reported because of nerve root damage, however, a typical meningeal syndrome is rarely observed $(10,11)$. 
Gadolinium-enhanced brain and spine magnetic resonance imaging (MRI) is the preferred radiographic method for establishing the diagnosis of LG. Although the neuroimaging features of LG are not very specific, they include enhanced visualization of the leptomeninges of the brain or spinal cord, the cranial nerves and the spinal nerve roots, the surface of the brain, the cerebellar foliae, and the inner region of the cerebral sulci (8). Unfortunately, the risk of false-negatives limits the use of MRI as a stand-alone diagnostic tool. The diagnosis of LG is usually confirmed by the presence of glioma cells in the CSF, which are possibly associated with high levels of CSF proteins (8).

Although several studies have looked for potential predictive factors of secondary LG occurrence, the prognostic factors of this disease at the time of diagnosis remain unknown. To date, the rarity and heterogeneous presentation of this disease has not allowed the development of a standard therapeutic approach (8). Recently, a standard response evaluation method (based on a standardized neurological examination, CSF cytology, and radiographic evaluation) was proposed by the Response Assessment in Neuro-Oncology (RANO) leptomeningeal metastases working group (12). The use of radiotherapy (13), systemic alkylating agents, such as temozolomide (TMZ) (4), and intrathecal cytarabine (14) or methotrexate (6) has been described only in case reports or in small retrospective cohorts, and to date, the prognosis of secondary LG remains poor, with the mean overall survival (OS) ranging from 2 to 4 months $(10,15,16)$.

Therefore, our objective was to evaluate the characteristics, the prognostic factors, as well as treatment options for patients with LG, with a focus on assessing whether there are any potential benefits in using BCNU-TMZ instead of other chemotherapeutic agents.

\section{Patients and Methods}

A retrospective monocentric analysis of 31 patients diagnosed with LG referred to our institution between 2004 and 2013 was conducted. The present study was approved by our local ethics committee and complies with the principles of the Declaration of Helsinki.

Patients. Patient characteristics at LG diagnosis are listed in Table I. Of the 31 patients examined, 12 were females and 19 were males, varying in age from 22 to 78 years and having a median age of 45.2 years. The diagnosis of LG was based on i) positive CSF cytology $(n=12)$, ii) MRI data $(n=16)$ with or without hyperproteinorrachia (CSF protein levels) (>1.2 gr/l); or iii) clinical data with hyperproteinorrachia $(n=3)$.

Method. The following data were obtained from the patients' charts: i) age, ii) Karnofsky performance status (KPS), iii) neurological symptoms (cognitive disturbance, motor or sensitivity deficit, aphasia, epilepsy, intracranial pressure, and meningism) at the time of LG diagnosis, iv) history of ventricular openings during glioma debulking surgery, v) treatments for glioma before the LG diagnosis, vi) the interval between initial glioma diagnosis (IGD) and LG diagnosis, vii) the presence of meningeal contrast enhancement, viii) the tumor location, ix) the tumor contact with CSF (defined by a minimum contact zone of $10 \mathrm{~mm}$ ), $\mathrm{x}$ ) the $\mathrm{LG}$ treatment modalities and their toxicities, xi) the administered BCNU-TMZ or any other type of chemotherapy (17), and xii) the results of the CSF analysis at the time of LG diagnosis and for the duration of the treatment (cytology, number of CSF elements, protein and glucose levels). For the disease assessment, imaging data were reviewed at the time of the study using the RANO criteria. Progression-free survival (PFS) was defined as the time from the LG diagnosis to documented progression or death, censored at the date of the last documented disease evaluation. Overall survival (OS) was defined as the time from the LG diagnosis to death from any cause, censored at the date of last communication. The date of LG diagnosis was defined as the date of positive cytology or the date of MRI diagnosis with negative CSF histology. The LG treatment toxicities were retrospectively assessed and graded based on the Common Terminology Criteria for Adverse Events v4.0 (18).

Data were described as frequencies (percentages) or medians (range), as appropriate. PFS, OS, and median OS were estimated using the Kaplan-Meier product limit method. The log-rank test was performed to compare survival rates obtained from the univariate analysis, and the Mann-Whitney test was performed to compare median delays. Qualitative variables were compared using the chisquare test. Prognostic factors with $p<0.05$ in univariate analysis were explored in the multivariate analysis. Cox proportional hazards models were used for multivariate analyses and for estimating the hazard ratios in the regression models. Reported $p$-values were 2sided, and $p<0.05$ was considered statistically significant. Statistical analyses were performed using the SPSS version $20^{\circledR}$ (SPSS, Inc., Chicago, IL, USA).

\section{Results}

Patient characteristics and outcomes. At the time of LG diagnosis, most patients $(22 / 31,71 \%)$ displayed a general status (KPS) of $<70$, showed cognitive disturbance and a motor or a sensitivity deficit (Table I). Thirty-six percent $(11 / 31)$ of the patients experienced meningism, while only $10 \%(3 / 31)$ experienced intracranial hypertension. A primary supratentorial tumor was found in $81 \%(25 / 31)$ of the patients, while a spinal or posterior fossa localized tumor was found in the remaining patients. Almost all patients with available imaging data $(25 / 31)$ showed a tumor in contact with CSF at the time of LG diagnosis.

The median times from IGD to LG occurrence tended to be shorter for patients with glioblastoma than for those with a grade II to III glioma ( 8 and 29 months, respectively; $p=0.08$ ).

Most patients received at least one treatment line before LG diagnosis. At the time of LG diagnosis, $71 \%$ of the patients received treatment (22/31). A majority of the treated patients were treated with BCNU-TMZ as the first-line treatment (15/22). Following LG diagnosis, 55\% (12/22) of patients were administered with bevacizumab as a first, 
Table I. Patient characteristics before LG Diagnosis.

\begin{tabular}{|c|c|c|}
\hline \multicolumn{3}{|l|}{ Characteristics } \\
\hline Age (median, range) & $45.2(21.6-77.9)$ & \\
\hline \multicolumn{3}{|l|}{ Gender } \\
\hline Male $(\mathrm{N}, \%)$ & $19 / 31$ & 61.3 \\
\hline Female $(\mathrm{N}, \%)$ & $12 / 31$ & 38.7 \\
\hline \multicolumn{3}{|l|}{ Grading } \\
\hline WHO grade II gliomas (N, \%) & $1 / 31$ & 3.2 \\
\hline WHO grade III gliomas $(\mathrm{N}, \%)$ & $10 / 31$ & 32.3 \\
\hline WHO grade IV gliomas (N, \%) & $20 / 31$ & 64.5 \\
\hline \multicolumn{3}{|l|}{ Histology } \\
\hline Low grade oligodendroglioma $(\mathrm{N}, \%)$ & $1 / 31$ & 3.2 \\
\hline Anaplastic astrocytoma $(\mathrm{N}, \%)$ & $5 / 31$ & 16.1 \\
\hline Anaplastic Oligodendroglioma $(\mathrm{N}, \%)$ & $5 / 31$ & 16.1 \\
\hline Glioblastoma $(\mathrm{N}, \%)$ & $20 / 31$ & 64.5 \\
\hline \multicolumn{3}{|l|}{ Interval between IGD and LG } \\
\hline (median months, range) & $13.5(0-241.9)$ & \\
\hline WHO grade II \& III gliomas (months, range) & $28.9(0-99.2)$ & \\
\hline WHO grade IV gliomas (months, range) & $8.1(0-241.9)$ & \\
\hline \multicolumn{3}{|l|}{ KPS at LG diagnostic } \\
\hline $70-80(\mathrm{~N}, \%)$ & $9 / 31$ & 29.0 \\
\hline $50-60(\mathrm{~N}, \%)$ & $22 / 31$ & 71.0 \\
\hline \multicolumn{3}{|l|}{ Symptoms at LG diagnostic } \\
\hline Cognitive disturbance $(\mathrm{N}, \%)$ & $23 / 31$ & 74.2 \\
\hline Motor or sensitivity deficit (N, \%) & $17 / 31$ & 54.8 \\
\hline Aphasia $(\mathrm{N}, \%)$ & $7 / 31$ & 23.3 \\
\hline Epilepsy $(\mathrm{N}, \%)$ & $4 / 31$ & 12.9 \\
\hline Intracranial hypertension $(\mathrm{N}, \%)$ & $3 / 31$ & 10.0 \\
\hline Meningism $(\mathrm{N}, \%)$ & $11 / 31$ & 35.5 \\
\hline \multicolumn{3}{|l|}{ Tumor location at LG } \\
\hline Posterior fossa $(\mathrm{N}, \%)$ & $1 / 31$ & 3.2 \\
\hline Spinal $(\mathrm{N}, \%)$ & $4 / 31$ & 12.9 \\
\hline Supratentorial $(\mathrm{N}, \%)$ & $25 / 31$ & 80.6 \\
\hline The three $(\mathrm{N}, \%)$ & $1 / 31$ & 3.2 \\
\hline \multicolumn{3}{|l|}{ Tumoral contact with CSF at the } \\
\hline time of $\mathrm{LG}$ diagnosis $(\mathrm{N}, \%)$ & $25 / 31$ & 92.6 \\
\hline Unknown & $4 / 31$ & \\
\hline \multicolumn{3}{|l|}{ Treatment before LG $(\mathrm{N}, \%)$} \\
\hline 0 line $(\mathrm{N}, \%)$ & $5 / 31$ & 16.2 \\
\hline 1 line $(N, \%)$ & $12 / 31$ & 38.7 \\
\hline$\geq 2$ lines $(\mathrm{N}, \%)$ & $14 / 31$ & 45.1 \\
\hline Patients with positive CSF cytology $(\mathrm{N}, \%)$ & $12 / 31$ & 46.2 \\
\hline Unknown & $5 / 31$ & \\
\hline
\end{tabular}

LG, Leptomeningeal gliomatosis; WHO, world health organization; IGD, initial glioma diagnosis; KPS, Karnofsky performance status; CSF, cerebrospinal fluid.

second or third line of treatment. Grade III to IV treatment toxicities (mainly hematological) were observed in $45.5 \%$ $(10 / 22)$ of the treated patients and in $47 \%(7 / 15)$ of patients treated with BCNU-TMZ (Table II). Among the 22 treated patients, $9(41 \%)$ were clinically stable or showed an improvement following chemotherapy (Table II). Only one patient was alive at the time of the last follow-up (22 months). The median PFS and OS from the time of the LG diagnosis were low: 1.8 months [95\% confidence interval
Table II. Patient outcomes

\begin{tabular}{lcr}
\hline Characteristics & & \\
\hline CSF proteins level during LG treatment & & \\
Increased (N, \%) & $4 / 11$ & 36.4 \\
Stable or decreased (N, \%) & $7 / 11$ & 63.6 \\
Treatment for LG (N, \%) & & \\
0 line (N, \%) & $9 / 31$ & 29 \\
1 line (N, \%) & $17 / 31$ & 54.8 \\
2-3 lines (N, \%) & $5 / 31$ & 16.1 \\
BCNU-TMZ as LG first line treatment (N, \%) & $15 / 31$ & 48.4 \\
Use of bevacizumab during LG treatment (N, \%) & $12 / 31$ & 38.7 \\
Disease assessment & & \\
Clinical assessment & & \\
Improved (N, \%) & $6 / 31$ & 19.3 \\
Stable (N, \%) & $3 / 31$ & 9.7 \\
Deteriorated (N, \%) & $22 / 31$ & 71 \\
Radiological parenchymal assessment & & \\
Response (N, \%) & $3 / 31$ & 9.7 \\
Stable (N, \%) & $7 / 31$ & 22.6 \\
Progression (N, \%) & $6 / 31$ & 19.3 \\
Not assessed & $15 / 31$ & 48.4 \\
Radiological meningeal assessment & & \\
Response (N, \%) & $3 / 31$ & 9.7 \\
Progression (N, \%) & $6 / 31$ & 19.3 \\
No meningeal contrast enhancement & $1 / 31$ & 3.2 \\
Not assessed & $15 / 31$ & 48.4 \\
\hline
\end{tabular}

CSF, Cerebrospinal fluid; LG, leptomeningeal gliomatosis; TMZ, temozolomide.

$(\mathrm{CI})=0.9-2.7)]$ and 2.1 months $(95 \% \mathrm{CI}=1.3-3)$, respectively. The 6- and 12-month OS rates were $26 \%$ and $6 \%$, respectively, whereas the 6- and 12-month PFS rates were $13 \%$ and $6 \%$, respectively.

Prognostic factors. In univariate analysis, administration of BCNU-TMZ as a first line of LG therapy increased the PFS and OS of patients compared to other types of chemotherapy ( $p=0.036$ and $p=0.08$ respectively, Figure 1 ). In addition, age at $<45.2$ years, KPS $\geq 70$, and a delay between glioma and LG diagnosis $\geq 13.45$ months were significantly associated with a better PFS and OS (Table III). Similarly, confirmation of oligodendroglioma through histological examination also showed significant improvement in PFS (Table III). No prognostic value was found in the initial grading, CSF protein levels, or CSF protein level evolution (range, $+41 \%$ to $+994 \%$ ) during the treatment for LG (Tables III and IV). The median OS values for patients treated with BCNUTMZ, patients treated with other types of chemotherapy, and untreated patients were $5.7(95 \% \mathrm{CI}=3.1-8.2), 2.0(95 \%$ $\mathrm{CI}=1.1-2.9)$, and $0.6(95 \% \mathrm{CI}=0.5-0.7)$ months, respectively (Table IV).

In the multivariate analysis (Table IV), BCNU-TMZ as the first-line treatment for $\mathrm{LG}(p=0.002 ; \mathrm{HR}=6.635)$ as well 

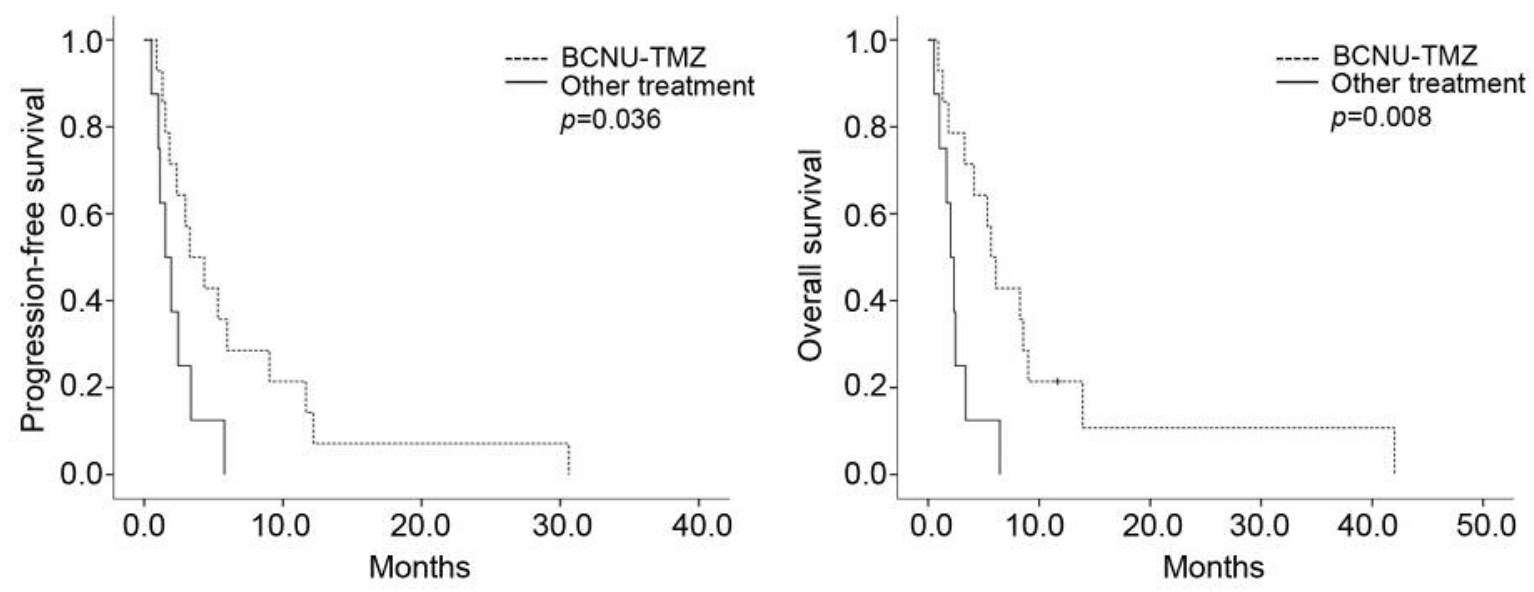

Figure 1. Kaplan-Meier estimates of progression-free survival and overall survival according to treatment groups.

as the delay between the IGD and LG diagnoses $(p=0.009$; $\mathrm{HR}=5.839$ ) were both independent prognostic predictors for OS. Similar results were observed for PFS (Table III).

Stable or improved clinical statuses under treatment were associated with a better initial KPS at the time of the LG diagnosis $(p=0.049)$ and these tended to associate with a brain tumor volume decrease $(p=0.059)$. However, no correlation was observed between the clinical status and the CSF protein levels at the time of LG diagnosis $(p=0.716)$, CSF protein level evolution $(p=0.652)$, or meningeal response $(p=0.231)$.

\section{Discussion}

The present retrospective analysis of patients with secondary LG identified the time interval from the IGD to the LG diagnosis as a potential prognostic factor for OS. Among the treatments used in our institution, BCNU-TMZ seems to be an interesting therapeutic option for these patients.

LG diagnosis is challenging because several pleomorphic clinical manifestations may be attributed to the primary glioma. In our cohort, $35 \%$ of the patients had meningism. To date, the diagnostic confirmation is based on the presence of glioma cells in the CSF. However, repetitive lumbar punctures appear to be necessary so as to confirm the LG diagnosis, due to the frequent presence of false-negative samples $(19,20)$. In this context, the improvement of MRI discrimination is an attractive tool for the diagnosis of these patients.

Literature on secondary LG remains inadequate; only a few case reports or retrospective cohort studies have been published so far, presenting limited amount of data in line with the rare incidence of the disease and the methodology described in them. Here, we report a median age of 45.2 years at the time of LG diagnosis, which is in line with one of the largest cohort studies by Noh et al. (6). The median time between IGD and LG diagnosis was 13.5 months, with a mean of 32.5 months and a range of 0-242 months. These results tend to be consistent with those reported by Arita et al. (15) and Witham et al. (21), who have suggested that LG remains an evolved stage of glioma even though the dissemination of glial cells in the CSF can occur earlier in certain cases.

The previous reports have suggested several risk factors associated with secondary LG dissemination, including intraoperative ventricular entry (2), proximity of the lesion to the ventricular system $(2,11,22,23)$, and PTEN mutation (24). In our study, we observed that $93 \%$ of tumors were in contact with the CSF drainage site at the time of LG diagnosis. However, it should be noted that our work focused on the prognostic factors at the time of LG diagnosis; therefore, the predictive factors of LG occurrence were out of our study's scope.

To our knowledge, the prognostic factors of LG at the time of diagnosis are poorly documented. In our study, we identified the duration of the interval between IGD and LG diagnosis as a prognostic predictor. The use of BCNU-TMZ was associated with a better patient outcome. Age, KPS, and histological grade according to the World Health Organization criteria did not seem to impact either PFS or OS, even though they are well-known prognostic factors for glioma at the time of the initial diagnosis. Furthermore, CSF protein levels at the time of LG diagnosis have often been described as a diagnostic tool (10); however, the evolution of CSF protein levels during LG treatment has failed to predict a better OS or PFS in our small retrospective study.

To date, no standard treatment has been established for LG while the benefits of chemotherapy remain controversial (25). 
Table III. Univariate and multivariate analyses of potential prognostic factors for progression-free survival in our population.

\begin{tabular}{|c|c|c|c|c|c|c|}
\hline \multirow[b]{2}{*}{ Parameters } & \multicolumn{3}{|c|}{ Univariate } & \multicolumn{3}{|c|}{ Multivariate } \\
\hline & PFS (months) & $95 \% \mathrm{CI}$ & $p$-Value & $\mathrm{HR}$ & $\mathrm{CI} 95 \%$ of $\mathrm{HR}$ & $p$-Value \\
\hline Age (years) & & & $<0.001$ & & & 0.258 \\
\hline$<45.2$ & 4.3 & $0.6-8.1$ & & & & \\
\hline$\geq 45.2$ & 0.9 & $0.6-1.2$ & & & & \\
\hline KPS & & & 0.024 & & & 0.793 \\
\hline$<70$ & 1.1 & $0-2.2$ & & & & \\
\hline$\geq 70$ & 5.3 & $0-14.0$ & & & & \\
\hline Grading at initial diagnosis & & & 0.344 & & & \\
\hline WHO grade 2 and 3 gliomas & 2.1 & $0.2-4.1$ & & & & \\
\hline WHO grade 4 gliomas & 1.3 & $0-2.8$ & & & & \\
\hline \multicolumn{7}{|l|}{ Histology at initial diagnosis } \\
\hline Oligodendroglioma & 3.4 & $0-8.0$ & 0.049 & & & 0.877 \\
\hline Others & 1.3 & $0.6-2.0$ & & & & \\
\hline No line before LG diagnosis & & & 0.786 & & & \\
\hline$\leq 1$ & 2.3 & $0.4-4.3$ & & & & \\
\hline$>1$ & 1.5 & 1.2 & & & & \\
\hline Tumor location & & & 0.294 & & & \\
\hline Infratentorial & 1.7 & $0-3.7$ & & & & \\
\hline Supratentorial & 2.3 & $1.7-2.9$ & & & & \\
\hline 1st line treatment for $L G$ & & & 0.036 & 3.864 & $1.340-11.139$ & 0.016 \\
\hline Contains BCNU-TMZ & 3.3 & $0.8-5.8$ & & & & \\
\hline Other treatment & 1.5 & $0.4-2.7$ & & & & \\
\hline CSF proteins level at LG diagnosis $(\mathrm{g} / \mathrm{L})$ & & & 0.549 & & & \\
\hline$<4.45$ (median) & 2.1 & $1.5-2.8$ & & & & \\
\hline$\geq 4.45$ (median) & 1.8 & $0.5-3.1$ & & & & \\
\hline CSF proteins level evolution during LG treatment $(\mathrm{g} / \mathrm{L})(\mathrm{N}=11)$ & & & 0.122 & & & \\
\hline Decreased & 6.0 & $4.3-7.7$ & & & & \\
\hline Increased & 1.5 & $0-3.3$ & & & & \\
\hline CSF glucose level at LG diagnosis $(\mathrm{mmol} / \mathrm{L})(\mathrm{N}=17)$ & & & 0.182 & & & \\
\hline$<2.4($ median $)$ & 1.1 & $0.4-1.8$ & & & & \\
\hline$>2.4($ median $)$ & 2.1 & $1.6-2.7$ & & & & \\
\hline Delay between glioma initial diagnosis and LG diagnosis (month) & & & 0.004 & 4.864 & $1.348-17.551$ & 0.026 \\
\hline$<13.45$ (median) & 1.0 & $0.7-1.3$ & & & & \\
\hline$\geq 13.45$ (median) & 2.1 & $0-4.9$ & & & & \\
\hline
\end{tabular}

PFS, Progression-free survival; CI, confidence interval; HR, hazard ration; CI95\%, 95\% confidence interval; KPS, Karnofsky performance status; WHO, world health organization; LG, leptomeningeal gliomatosis; TMZ, temozolomide; CSF, cerebrospinal fluid.

In high-grade gliomas, Bae et al. (10) have used intrathecal methotrexate chemotherapy, with or without bevacizumab plus irinotecan; however, these therapies did not show any significant effect on OS. Chamberlain et al. (26) used intraventricular chemotherapies in 18 patients with high grade gliomas and he concluded that these therapies had minimal palliative efficacy and that additional supportive care should be seriously considered. Nevertheless, Beauchesne et al. (14) and Nandipati et al. (4) have reported interesting clinical improvements and radiological responses amongst patients treated with intrathecal cytarabine and TMZ, respectively. However, these results remain isolated, and no clear approach for the management of $L G$ can be determined on the basis of these literature reports. Among the treatments used following diagnosis of LG, we found that the effects of BCNU-TMZ were associated with a better patient outcome when compared to other types of chemotherapy. Therefore, according to these results, BCNU-TMZ could be an attractive therapeutic option for the treatment of patients with secondary LG as well. Indeed, BCNU and TMZ are two of the most potent drugs used to treat malignant gliomas and the preclinical in vitro studies of Plowman et al. (27) have showed that they display a synergistic therapeutic effect in treating glioma. TMZ determines depletion of O6-alkylguanine DNA transferase (O6-AGT), which is one of the causes of the nitrosourea resistance $(27,28)$. Furthermore, TMZ has a favorable safety profile with mild toxicities that do not overlap with those of BCNU (28).

Our study was limited in that it was performed retrospectively and included data from only one medical 
Table IV. Univariate and multivariate analyses of potential prognostic factors for overall survival in our population.

\begin{tabular}{|c|c|c|c|c|c|c|}
\hline \multirow[b]{2}{*}{ Factors } & \multicolumn{3}{|c|}{ Univariate } & \multicolumn{3}{|c|}{ Multivariate } \\
\hline & OS (months) & $95 \% \mathrm{CI}$ & $p$-Value & HR & CI95\% of $\mathrm{HR}$ & $p$-Value \\
\hline Age (years) & & & $<0.001$ & & & 0.074 \\
\hline$<45.2$ & 6.1 & $4.7-7.5$ & & & & \\
\hline$\geq 45.2$ & 0.9 & $0.6-1.2$ & & & & \\
\hline KPS & & & 0.012 & & & 0.818 \\
\hline$<70$ & 1.1 & $0-2.2$ & & & & \\
\hline$\geq 70$ & 6.4 & $4.1-8.8$ & & & & \\
\hline Grading & & & 0.343 & & & \\
\hline WHO grade 2 and 3 gliomas & 3.3 & $1.4-5.1$ & & & & \\
\hline WHO grade 4 gliomas & 1.8 & $0.3-3.3$ & & & & \\
\hline \multicolumn{7}{|l|}{ Histology at initial diagnosis } \\
\hline Oligodendroglioma & 3.3 & $1.4-5.1$ & 0.343 & & & \\
\hline Others & 1.8 & $0.3-3.3$ & & & & \\
\hline No line before LG diagnosis & & & 0.769 & & & \\
\hline$\leq 1$ & 2.4 & $0-5.5$ & & & & \\
\hline$>1$ & 2.0 & $1.1-2.9$ & & & & \\
\hline Tumor location & & & 0.193 & & & \\
\hline Infratentorial & 1.7 & $0-3.7$ & & & & \\
\hline Supratentorial & 2.1 & $1.3-3.0$ & & & & \\
\hline 1st line treatment for $L G$ & & & 0.008 & 6.635 & $1.988-22.150$ & 0.002 \\
\hline Contains BCNU-TMZ & 5.7 & $4.2-7.1$ & & & & \\
\hline Other treatment & 2.0 & $1.1-2.9$ & & & & \\
\hline CSF proteins level at LG diagnosis $(\mathrm{g} / \mathrm{L})$ & & & 0.932 & & & \\
\hline$<4.45$ (median) & 3.4 & $0.3-6.5$ & & & & \\
\hline$\geq 4.45$ (median) & 1.8 & $0.5-3.1$ & & & & \\
\hline CSF proteins level evolution during LG treatment $(\mathrm{g} / \mathrm{L})(\mathrm{N}=11)$ & & & 0.293 & & & \\
\hline Decreased & 8.3 & $1.6-15.0$ & & & & \\
\hline Increased & 4.1 & $0-10.3$ & & & & \\
\hline CSF glucose level at LG diagnosis $(\mathrm{mmol} / \mathrm{L})(\mathrm{N}=17)$ & & & 0.121 & & & \\
\hline$<2.4($ median $)$ & 1.3 & $0.1-2.6$ & & & & \\
\hline$>2.4($ median $)$ & 4.1 & $0-9.9$ & & & & \\
\hline Delay between initial glioma diagnosis and LG diagnosis (month) & & & 0.003 & 5.839 & $1.565-21.779$ & 0.009 \\
\hline$<13.45$ (median) & 1.0 & $0.7-1.3$ & & & & \\
\hline$\geq 13.45$ (median) & 3.4 & $0-9.3$ & & & & \\
\hline
\end{tabular}

OS, Overall survival; CI, confidence interval; HR, hazard ration; CI95\%, 95\% confidence interval; KPS, Karnofsky performance status; WHO, world health organization; LG, leptomeningeal gliomatosis; TMZ, temozolomide; CSF, cerebrospinal fluid.

center. Despite these limitations, we carefully analyzed all patients referred to our institution, who were further followed-up and were diagnosed for secondary LG.

We retrospectively observed 31 cases of secondary LG and identified the time interval from the IGD to the LG diagnosis as a potential prognostic factor for LG; however, initial proteinorrachia and its evolution during the course of the treatment do not correlate with the patients' outcome. Instead, we found that BCNU-TMZ may be a beneficial therapeutic option in this setting.

\section{Conflicts of Interest}

The Authors declare that they have no conflicts of interest.

\section{Acknowledgements}

This work was supported by the Association pour la Recherche sur les Tumeurs Cérébrales Sud and the SIRIC of Marseilles (grant no.INCa-DGOS-Inserm 6038).

\section{References}

1 Lepreux S, Sagnier S, Perez J-T, Léger F, Sibon I and Vital A: Primary diffuse leptomeningeal gliomatosis: do we miss the diagnosis? Clin Neuropathol 36: 222-226, 2017.

2 Lawton CD, Nagasawa DT, Yang I, Fessler RG and Smith ZA: Leptomeningeal spinal metastases from glioblastoma multiforme: treatment and management of an uncommon manifestation of disease. J Neurosurg Spine 17: 438-448, 2012. 
3 Louis DN, Perry A, Reifenberger G, von Deimling A, FigarellaBranger D, Cavenee WK, Ohgaki H, Wiestler OD, Kleihues P and Ellison DW: The 2016 World Health Organization Classification of Tumors of the Central Nervous System: a summary. Acta Neuropathol (Berl) 131: 803-820, 2016.

4 Nandipati S and Demopoulos A: Leptomeningeal dissemination of anaplastic glioma: prolonged survival in two patients treated with temozolomide. J Neurooncol 105: 663-665, 2011.

5 Stark AM, Nabavi A, Mehdorn HM and Blömer U: Glioblastoma multiforme-report of 267 cases treated at a single institution. Surg Neurol 63: 162-169, 2005.

6 Noh J-H, Lee MH, Kim WS, Lim DH, Kim ST, Kong D-S, Nam D-H, Lee J-I and Seol HJ: Optimal treatment of leptomeningeal spread in glioblastoma: analysis of risk factors and outcome. Acta Neurochir (Wien) 157: 569-576, 2015.

7 Erlich SS and Davis RL: Spinal subarachnoid metastasis from primary intracranial glioblastoma multiforme. Cancer 42: 28542864, 1978.

8 Le Rhun E, Rudà R, Devos P, Hoang-Xuan K, Brandsma D, Pérez Segura P, Soffietti R and Weller M: Diagnosis and treatment patterns for patients with leptomeningeal metastasis from solid tumors across Europe. J Neurooncol 133: 419-427, 2017.

9 Gleissner B and Chamberlain MC: Neoplastic meningitis. Lancet Neurol 5: 443-452, 2006.

10 Bae J-S, Yang S-H, Yoon W-S, Kang S-G, Hong Y-K and Jeun S-S: The clinical features of spinal leptomeningeal dissemination from malignant gliomas. J Korean Neurosurg Soc 49: 334-338, 2011.

11 Vertosick FT and Selker RG: Brain stem and spinal metastases of supratentorial glioblastoma multiforme: a clinical series. Neurosurgery 27: 516-522, 1990.

12 Chamberlain M, Junck L, Brandsma D, Soffietti R, Rudà R, Raizer J, Boogerd W, Taillibert S, Groves MD, Le Rhun E, Walker J, van den Bent M, Wen PY and Jaeckle KA: Leptomeningeal metastases: a RANO proposal for response criteria. Neuro-Oncol 19: 484-492, 2017.

13 Endo H, Kumabe T, Jokura H, Shirane R, Ariga H, Takai Y and Yoshimoto $\mathrm{T}$ : Leptomeningeal dissemination of cerebellar malignant astrocytomas. J Neurooncol 63: 191-199, 2003.

14 Beauchesne P, Blonski $\mathrm{M}$ and Brissart $\mathrm{H}$ : Response to intrathecal infusions of Depocyt ${ }^{\circledR}$ in secondary diffuse leptomeningeal gliomatosis. A case report. Vivo Athens Greece 25: 991-993, 2011.

15 Arita $N$, Taneda $M$ and Hayakawa $T$ : Leptomeningeal dissemination of malignant gliomas. Incidence, diagnosis and outcome. Acta Neurochir (Wien) 126: 84-92, 1994.

16 Shahideh M, Fallah A, Munoz DG and Loch Macdonald R: Systematic review of primary intracranial glioblastoma multiforme with symptomatic spinal metastases, with two illustrative patients. J Clin Neurosci Off J Neurosurg Soc Australas 19: 1080-1086, 2012.
17 Barrié M, Couprie C, Dufour H, Figarella-Branger D, Muracciole X, Hoang-Xuan K, Braguer D, Martin PM, Peragut JC, Grisoli $\mathrm{F}$ and Chinot O: Temozolomide in combination with BCNU before and after radiotherapy in patients with inoperable newly diagnosed glioblastoma multiforme. Ann Oncol Off J Eur Soc Med Oncol 16: 1177-1184, 2005.

18 Common Terminology Criteria for Adverse Events v.4.0 (CTCAE v.4.0) (http://evs.nci.nih.gov/ftp1/CTCAE_4.03_201006-14_QuickReference_8.5X11.pdf), 2010.

19 Onda K, Tanaka R, Takahashi H, Takeda N and Ikuta F: Cerebral glioblastoma with cerebrospinal fluid dissemination: a clinicopathological study of 14 cases examined by complete autopsy. Neurosurgery 25: 533-540, 1989.

20 Bigner SH and Johnston WW: The cytopathology of cerebrospinal fluid. II. Metastatic cancer, meningeal carcinomatosis and primary central nervous system neoplasms. Acta Cytol 25: 461-479, 1981.

21 Witham TF, Fukui MB, Meltzer CC, Burns R, Kondziolka D and Bozik ME: Survival of patients with high grade glioma treated with intrathecal thiotriethylenephosphoramide for ependymal or leptomeningeal gliomatosis. Cancer 86: 1347-1353, 1999.

22 Grabb PA, Albright AL and Pang D: Dissemination of supratentorial malignant gliomas via the cerebrospinal fluid in children. Neurosurgery 30: 64-71, 1992.

23 Elliott JP, Keles GE, Waite M, Temkin N and Berger MS: Ventricular entry during resection of malignant gliomas: effect on intracranial cerebrospinal fluid tumor dissemination. J Neurosurg 80: 834-839, 1994.

24 Kato H, Fujimura M, Kumabe T, Ishioka C, Kanamaru R and Yoshimoto T: PTEN gene mutation and high MIB-1 labeling index may contribute to dissemination in patients with glioblastoma. J Clin Neurosci Off J Neurosurg Soc Australas 11: 37-41, 2004.

25 Roldán G, Scott J, George D, Parney I, Easaw J, Cairncross G, Forsyth $\mathrm{P}$ and Yan E: Leptomeningeal disease from oligodendroglioma: clinical and molecular analysis. Can J Neurol Sci J Can Sci Neurol 35: 204-209, 2008.

26 Chamberlain MC: Combined-modality treatment of leptomeningeal gliomatosis. Neurosurgery 52: 324-330, 2003.

27 Plowman J, Waud WR, Koutsoukos AD, Rubinstein LV, Moore TD and Grever MR: Preclinical antitumor activity of temozolomide in mice: efficacy against human brain tumor xenografts and synergism with 1,3-bis(2-chloroethyl)-1nitrosourea. Cancer Res 54: 3793-3799, 1994.

28 Prados M: Temozolomide in combination with other cytotoxic agents. Semin Oncol 28: 24-33, 2001.

Received December 5, 2018

Revised December 27, 2018

Accepted January 3, 2019 